\title{
Implementasi Sistem Bel Rumah Otomatis berbasis Sensor Ultrasonik
}

\section{SINANTYA FERANTI ANINDYA, HENDI HANDIAN RACHMAT}

\author{
Jurusan Teknik Elektro Institut Teknologi Nasional Bandung \\ E-mail: sinantya.f.anindya@gmail.com
}

\begin{abstract}
ABSTRAK
Pada penelitian ini, modul ultrasonik dimanfaatkan dalam sebuah sistem bel otomatis sederhana. Sistem ini didesain untuk mempermudah pengunjung yang kesulitan menekan bel rumah konvensional, misalnya anak-anak dan penyandang cacat. Tujuan dari penelitian ini adalah mengevaluasi jarak optimal obyek secara vertikal dan horizontal di depan pintu agar dapat mengaktifkan bel secara otomatis. Sistem ini terdiri atas tiga unit yaitu modul ultrasonik HC-SRO4, modul pengolah data berbasis mikrokontroler dan modulbuzzer elektromagnetik. Sistem ini beroperasi dengan mendeteksi keberadaan pengunjung menggunakan sensor ultrasonik; saat pengunjung berada dalam jangkauan sensor, maka bel akan berbunyi selama lima detik sebelum memasuki kondisi diampada lima detik selanjutnya untuk mengurangi bunyi berulang selama tamu belum memasuki rumah. Untuk menguji kinerja sistem, bel otomatis dipasang pada kusen dengan kemiringan antara 15 hingga 20 derajat dari pintu daun pintu. Berdasarkan hasil pengujian, dapat disimpulkan bahwa sistem bel otomatis dapat berfungsi saat mendeteksi pengunjung dengan tinggi minimum $101 \mathrm{~cm}$ (secara vertikal) dan pada jarak rata-rata 45,33 cm dari pintu (secara horizontal).
\end{abstract}

Kata kunci: bel rumah, otomatis, penyandang cacat, sensor ultrasonik.

\begin{abstract}
In this research, ultrasonic module is used to develop a simple automatic doorbell system. The system was implemented to help some visitors who are difficultto press a switch of conventional doorbell, such as a child and a disabled people. The aim of this study is to evaluate an optimal vertical and horizontal distance of an object in front of the door where can activate the doorbell system automatically. There are three main modules to implement the system i.e. ultrasonic sensor module; microcontroller based processing unit module; and buzzer module. The sensor module, which installed in the upper side of a door frame with approximately 15 to 20 degrees angle from the door, detects the distances of visitor. The buzzer module will active for five seconds when the visitor in the detection range of the sensor. The results showed that the buzzer module will be active when the sensor detected an object with $101 \mathrm{~cm}$ of minimum height (vertically) and $45.33 \mathrm{~cm}$ of average distance from the door (horizontally).
\end{abstract}

Keywords: automatic, doorbell system, ultrasonic sensor, disabled people 


\section{PENDAHULUAN}

Seiring dengan perkembangan zaman, sistem otomasi rumah menjadi suatu kebutuhan tersendiri bagi kelompok masyarakat tertentu, khususnya bagi mereka yang kerap meninggalkan rumah atau berkewajiban merawat anggota keluarga yang cacat atau berusia lanjut. Teknologi yang semakin maju mendukung sistem otomasi rumah yang semakin mudah untuk diakses dan diaplikasikan, baik itu untuk hal sederhana seperti membuka pintu dengan sendirinya hingga aplikasi yang lebih rumit seperti home monitoring.

Bel otomatis merupakan salah satu aspek dari sistem otomasi rumah. Sesuai namanya, bel ini akan berbunyi dengan sendirinya saat mendeteksi keberadaan tamu. Terdapat beragam alasan yang dapat melatarbelakangi pemasangan bel otomatis, mulai dari sekadar mempermudah pengunjung hingga mengaplikasikannya untuk sistem anti-maling.

Agar dapat berfungsi, maka sistem bel otomatis harus mampu mendeteksi obyek di hadapan pintu. Salah satu sensor yang dapat digunakan untuk mendeteksi keberadaan obyek tersebut adalah sensor ultrasonik. Penggunaan sensor untuk membunyikan bel menyebabkan kebutuhan terhadap saklar bel akan tereliminasi sehingga memudahkan tamu dalam memberitahukan tuan rumah akan kehadiran mereka.

Sensor jenis ini telah banyak diaplikasikan untuk mendeteksi keberadaan suatu benda pada penelitian sebelumnya sepeti diaplikasikan untuk mendeteksi keberadaan suatu obyek di sekitar mobil ketika sedang melakukan parkir (Susanto dkk., 2007) dan mendeteksi jarak aman ke kendaraan lain ketika sedang dalam keadaan berjalan (Prawiroredjo \& Asteria, 2008). Sensor ini juga dapat diaplikasikan untuk mengukur tinggi suatu obyek seperti ketinggian level air (Arief, 2011), tinggi badan (Karyadi dan Gunawan, 2007). Dengan menggunakan sensor ini maka akan terdeteksi jarak atau posisi tertentu seseorang di depan pintu baik secara horisontal maupun vertikal untuk dapat menyalakan bel secara otomatis.

Pada penelitian ini dilakukan perancangan dan implementasi sistem bel rumah otomatis sederhana guna mengevaluasi range tinggi badan seseorang yang dapat dideteksi oleh sensor yang ditempatkan di atas pintu dan jarak optimal seseorang dari depan pintu untuk dapat menyalakan bel secara otomatis. Target pengguna alat ini adalah orang-orang yang berpotensi mengalami kesulitan dalam mengakses bel rumah konvensional, misalnya anakanak dan penyandang cacat.

Sebagai tahap awal penelitian ini, maka dilakukan beberapa pembatasan ruang lingkup penelitian yaitu sebagai berikut:

1. Jenis bel yang digunakan adalah buzzer elektromagnetik dengan catu daya 5 volt DC.

2. Jumlah sensor ultrasonik yang digunakan adalah satu unit.

3. Sistem ini didesain dengan asumsi hanya terdapat satu orang di depan pintu.

4. Jala-jala listrik dalam keadaan aktif.

\section{GAMBARAN UMUM SISTEM}

Sistem bel rumah otomatis ini terdiri dari beberapa komponen yaitu modul sensor ultrasonik, modul pengolah data, modul buzzer dan modul catu daya. Hubungan keempat modul ini digambarkan dalam suatu diagram blok seperti diperlihatkan pada Gambar 1. 


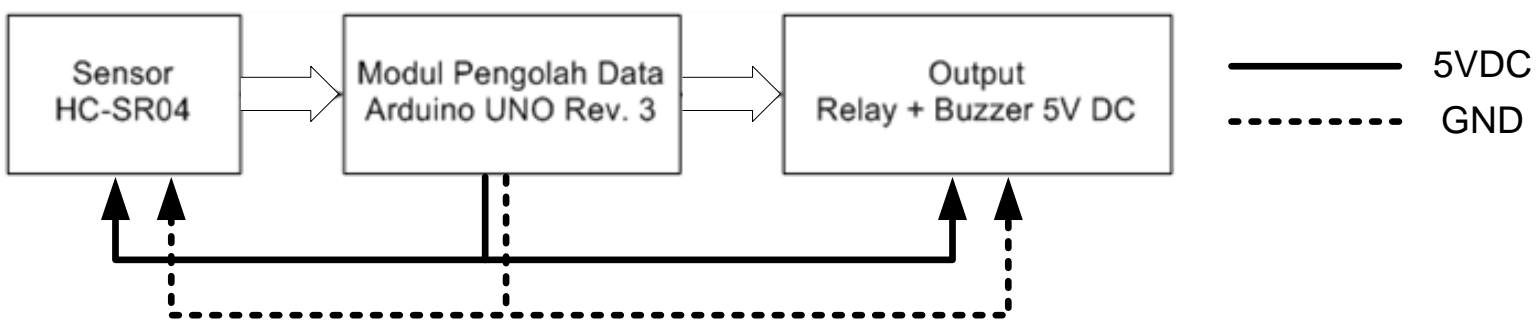

Gambar 1. Diagram blok sistem bel rumah otomatis

Secara sederhana sistem bel ini memiliki cara kerja sebagai berikut: sensor ultrasonik akan mendeteksi keberadaan suatu benda (obyek) di depan pintu rumah. Jika jarak dan posisi benda tersebut berada pada range yang ditentukan, maka buzzer yang berfungsi sebagai bel rumah akan aktif (berbunyi). Melalui sistem ini, seseorang (terutama penderita tuna netra) tidak perlu menekan tombol bel sehingga memudahkan penderita tuna netra untuk dibukakan pintu rumahnya. Sistem ini pun bermanfaat bagi pemilik rumah jika terdapat seseorang yang tidak diinginkan berada di depan pintu rumah.

Seluruh sistem ini dikontrol oleh modul pengolah data berbasis mikrokontroler baik untuk mengaktifkan sensor ultrasonik, menghitung jarak dan posisi yang ditentukan serta mengaktifkan buzzer. Catu daya yang digunakan oleh sistem pada penelitian saat ini masih menggunakan catu daya dari port USB komputer laptop dengan tegangan 5 Volt DC.

\section{METODE PERANCANGAN DAN PENGUJIAN}

Pada bagian ini akan dijelaskan secara lebih detail mengenai metoda perancangan modulmodul pendukung sistem serta pengujian yang akan dilakukan pada sistem, sehingga dapat dievaluasi rentang tinggi badan seseorang yang dapat dideteksi oleh sensor yang ditempatkan di atas pintu dan jarak optimal seseorang dari depan pintu untuk dapat menyalakan bel secara otomatis. Spesifikasi sistem bel pintu otomatis ini diperlihatkan pada Tabel 1.

Tabel 1: Spesifikasi Sistem Bel Otomatis

\begin{tabular}{|c|c|}
\hline Suplai Tegangan & 5 volt DC \\
\hline Tinggi Minimum Target & $107 \mathrm{~cm}$ \\
\hline Jarak Maksimum & $40 \mathrm{~cm}$ \\
\hline Akurasi & $\pm 10 \mathrm{~cm}$ \\
\hline
\end{tabular}

Sistem bel rumah otomatis terdiri atas perangkat keras dan perangkat lunak. Perangkat keras sistem ini terdiri dari modul pengolah data berupa modul sensor ultrasonik HC-SR04, modul pengolah data Arduino UNO, modul buzzer 5 volt DC dan modul catu daya DC 5 volt. 


\subsection{Metoda Perancangan dan Realisasi Perangkat Keras}

\section{a. Modul sensor ultrasonik HC-SR04}

Modul HC-SR04 (Gambar 2) merupakan modul sensor ultrasonik yang memiliki fungsi utama sebagai pengukur jarak. Modul ini terdiri atas sepasang transduser dengan empat pin, yaitu pin suplai tegangan $\left(\mathrm{V}_{\mathrm{cc}}\right)$, pin trigger, pin echo, dan pin ground. Modul akan memulai pengukuran saat diberi sinyal pulsa trigger sepanjang $10 \mu \mathrm{s}$, di mana transmitter akan mengirimkan gelombang ultrasonik yang akan diterima kembali oleh receiver saat gelombang tersebut mengenai obyek dan memantul.

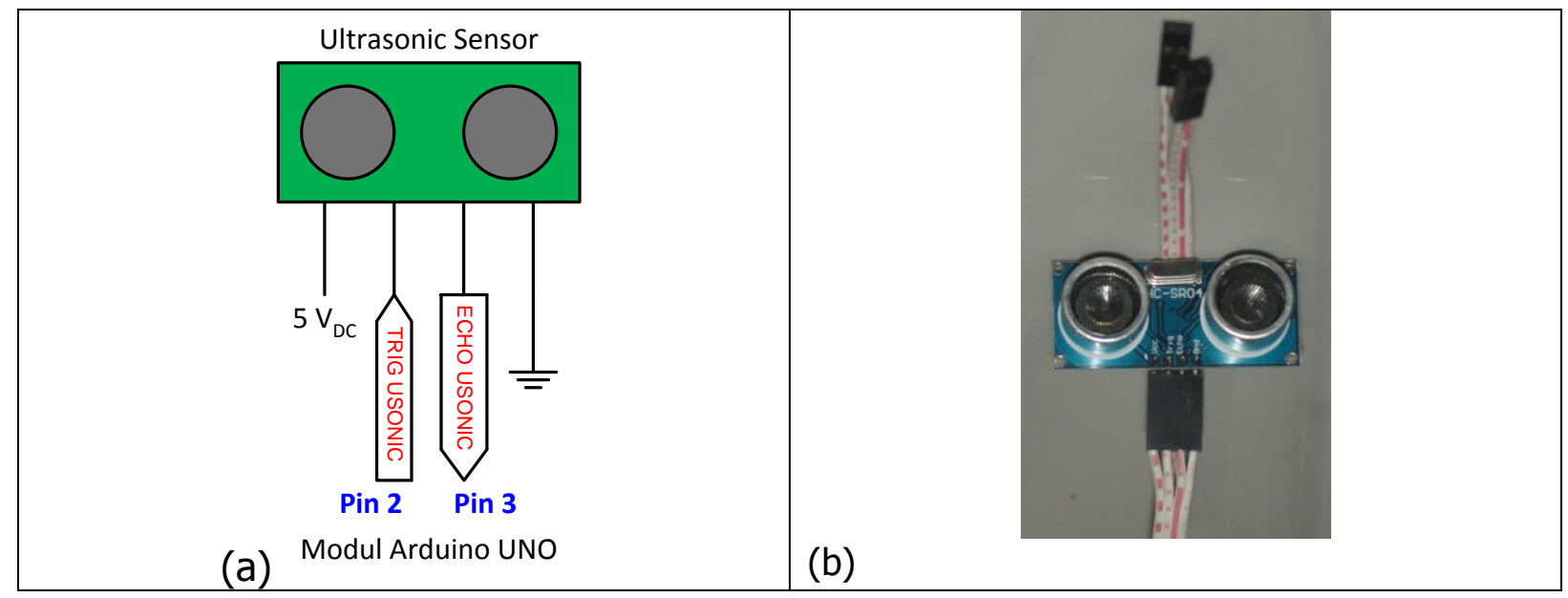

Gambar 2.(a) Diagram skematik dan (b) bentuk fisik modul sensor ultasonik HC-SR04

Pengukuran jarak berbasis ultrasonik dapat dilakukan dengan dua metode yaitu:

1. Perhitungan waktu tempuh

Pada medium rambat udara, gelombang ultrasonik memiliki kecepatan tempuh $340 \mathrm{~m} / \mathrm{s}$. Berdasarkan nilai tersebut, pengukuran jarak dapat dilakukan dengan mengamati waktu tempuh gelombang dari transmitter hingga diterima oleh receiver. Mengingat jarak yang ditempuh gelombang bersifat bolak-balik, maka perhitungan jarak metode ini berdasarkan datasheet sensor (http:// www.micropik.com/PDF/HCSR04.pdf) adalah:

$$
\text { Distance }=\frac{340 \times t}{2} \mathrm{~m}
$$

2. Perhitungan jumlah pulsa (http://www.micropik.com/PDF/HCSR04.pdf)

Transmitter akan mengeluarkan deretan pulsa burst dengan nilai tertentusaat diberikan pulsa trigger. Untuk setiap satu sentimeter, jumlah pulsa yang dihasilkan adalah 29 pulsa, sehingga jarak tempuh total dapat dihitung berdasarkan jumlah pulsa yang diterima oleh receiver. Seperti halnya metode pertama, jalan tempuh deretan pulsa bersifat bolak-balik sehingga perhitungannya berdasarkan datasheet menjadi:

$$
\text { Distance }=\frac{\text { pulse count }}{58} \mathrm{~cm}
$$




\section{b. Modul Arduino UNO}

Modul Arduino UNO seperti terlihat pada Gambar 3 merupakan modul pengolah data berbasis sistem mikrokontroler berbasis ATMega328. Sistem ini terdiri atas 14 pin I/O digital dan 6 pin input analog dengan kristal $16 \mathrm{MHz}$. Untuk suplai tegangan, Arduino UNO dapat disuplai langsung saat terhubung dengan Personal Computer (PC)atau computer laptop melalui port USB atau dengan suplai eksternal 7 hingga 12 volt. Pada sistem ini juga terdapat dua pin suplai tegangan DC, masing-masing bernilai 3,3 volt dan 5 volt. Dalam perancangan yang dilakukan, modul ultrasonik (pin 2 dan pin 3) dan modul buzzer(pin 5) dihubungkan dan dikontrol oleh modul ini, serta suplai tegangan 5 Volt DC kedua modul tersebut disuplai juga oleh modul ini.

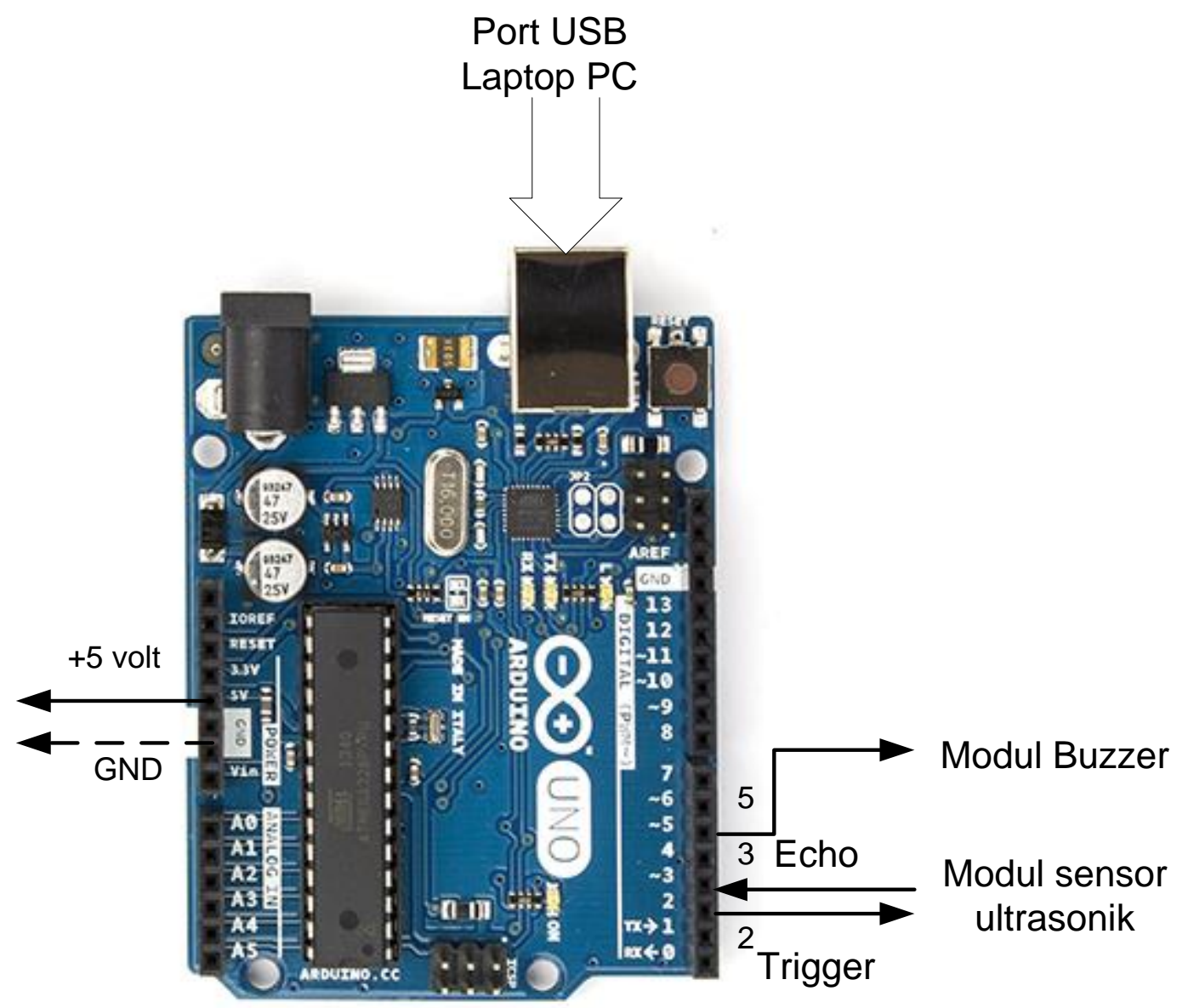

Gambar 3. Bentuk fisik modul Arduino UNO

(Sumber: www.arduino.cc/en/Main/arduinoBoardUno)

\section{c. Modul Buzzer Elektromagnetik}

Modul ini terdiri dari rangkaian driver buzzer berbasis relay dan komponen buzzer elektromagnetik. Pada Gambar 4 diperlihatkan skematik diagram dari modul buzzer yang direalisasikan pada sistem ini. 


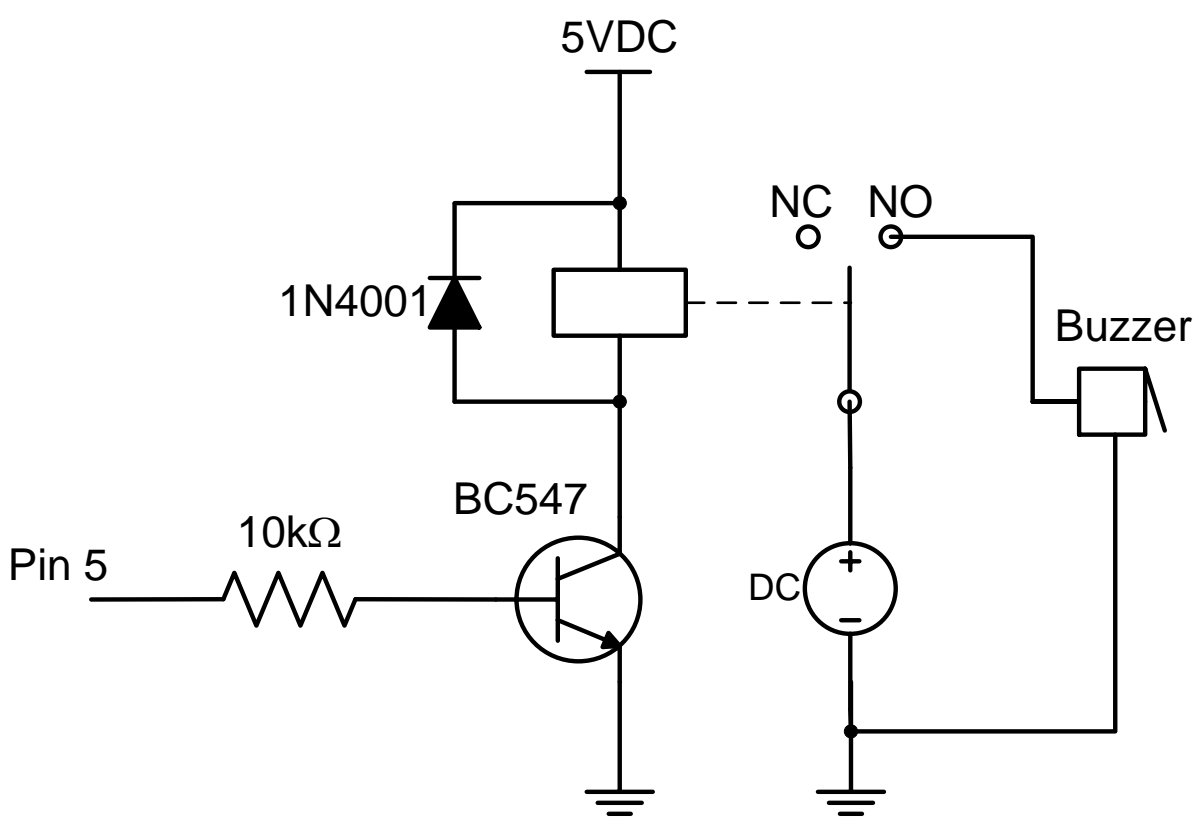

Gambar 4. Skematik diagram modul buzzer

Rangkaian driver berbasis relay digunakan untuk mengaktifkan komponen buzzer yang dikontrol oleh modul pengolah data melalui pin 5 dengan memberikan logika High. Dengan adanya logika High tersebut maka transistor akan mengalami saturasi sehingga coil pada relay akan dialiri arus listrik yang mengakibatkan terjadinya medan magnet. Medan magnet ini akan mengaktifkan saklar (Normaly open = NO) menjadi rangkaian tertutup yang mengakibtkan buzzer berbunyi. Untuk menon-aktifkan buzzer, maka modul rangkaian ini harus diberikan logika Low oleh modul pengolah data melalui pin 5.

Penggunaan rangkaian relay pada modul ini bertujuan untuk pengembangan sistem ke depan yaitu jika menggunakan bel listrik yang telah ada di pasaran. Komponen buzzer yang digunakan pada modul ini memiliki struktur seperti diperlihatkan pada Gambar 5.

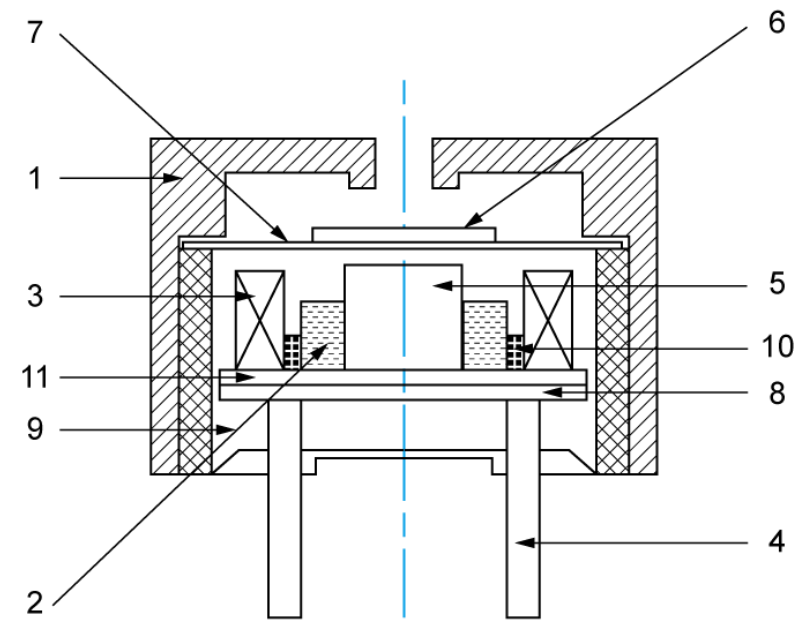

\begin{tabular}{|c|l|}
\hline No. & Name \\
\hline 1 & Housing \\
\hline 2 & Winding Coil \\
\hline 3 & Magnet \\
\hline 4 & Pin \\
\hline 5 & Pin Armiture \\
\hline 6 & Weight Diaphragm \\
\hline 7 & Plate Diaphragm \\
\hline 8 & P. C. Board \\
\hline 9 & Epoxy \\
\hline 10 & Silicon Rubber \\
\hline 11 & Plate Armiture \\
\hline
\end{tabular}

Gambar 5. Struktur buzzer elektromagnetik (Sumber: http://www.hs-buzzer.com/technology/Magnetic Buzzer) 


\subsection{Metoda Perancangan dan Realisasi Perangkat Lunak}

Pada modul pengolah data juga terdapat perangkat lunak berupa program berbasis bahasa $\mathrm{C}$ untuk mengatur operasi rangkaian relay terhadap hasil pembacaan sensor. Diagram alir program dapat diamati pada Gambar 6.

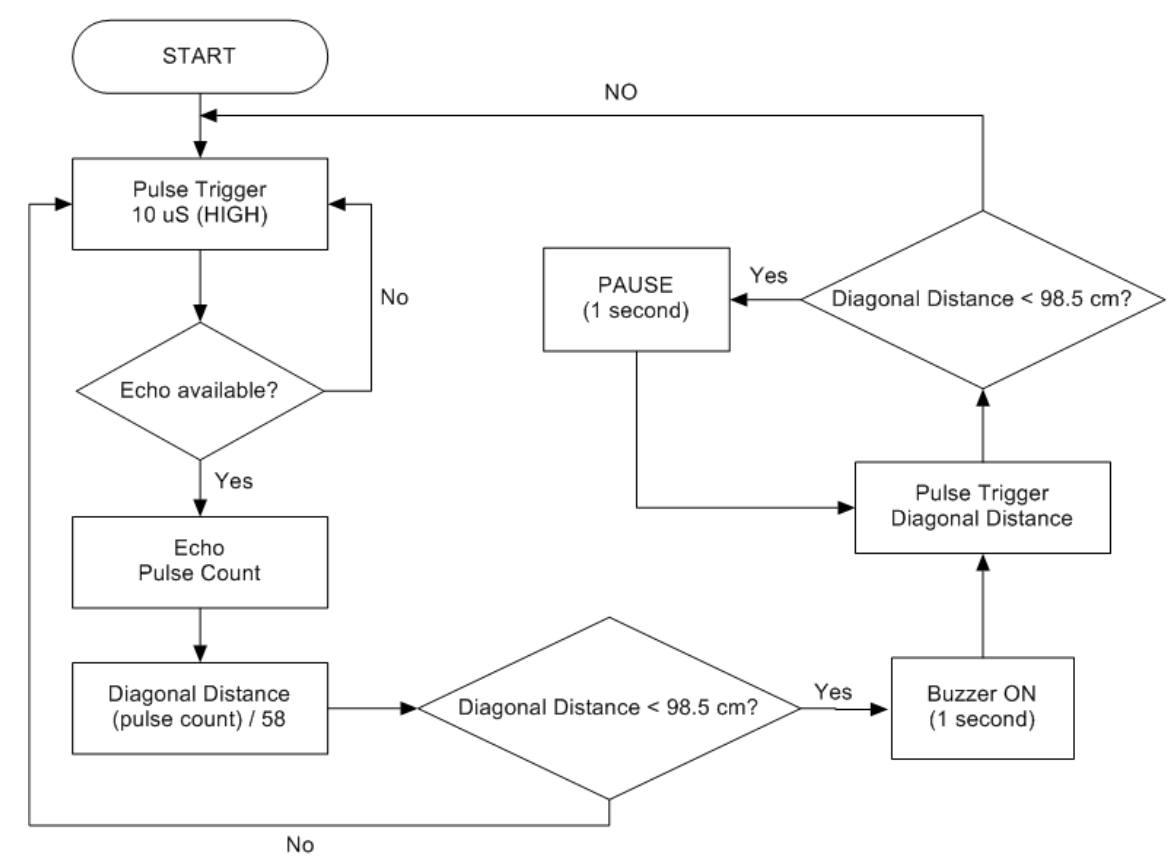

Gambar 6. Diagram alir program dari sistem bel otomatis

Berdasarkan perancangan yang dilakukan, maka sistem bel rumah otomatis memiliki cara kerja sebagai berikut: bel akan aktif untuk hasil pembacaan sensor ultrasonik pada range tertentu. Untuk mencapai kondisi tersebut, modul pengolah data dihubungkan dengan sensor dan transistor yang merupakan bagian dari rangkaian relay untuk kemudian dihubungkan ke buzzer.

Pembacaan sensor dimulai dengan pengiriman sinyal pulsa high selama $10 \mu \mathrm{s}$ pada pin trigger sensor, sehingga sensor ultrasonik menghasilkan pulsa burst. Saat mengenai obyek pada range sensor, pulsa tersebut akan memantul dan diterima oleh pin echo. Dengan diterimanya sinyal pulsa pada pin echo, maka pin yang terhubung dengan transistor akan bernilai high sehingga transistor akan berada dalam kondisi saturasi dan mengaktifkan relay.

Karenabuzzer dihubungkan dengan kontak normally-open (NO) dari relay, maka buzzer akan terhubung dengan catu daya saat relay aktif. Buzzer hanya akan berbunyi satu kali setelah pengunjung terdeteksi oleh sensor ultrasonik dan tidak akan berbunyi kembali hingga pengunjung sebelumnya keluar dari jangkauan sensor.

\subsection{Metode Pengujian}

Untuk menguji sistem bel otomatis, maka sensor ultrasonik dari sistem akan dipasangkan pada kusen pintu. Sensor dipasang dengan kemiringan antara 15 hingga 20 derajat dari pintu seperti terlihat pada Gambar 7. Hal ini bertujuan untuk memberikan ruang yang cukup bagi sensor untuk mendeteksi keberadaan tamu dan mengaktifkan bel listrik. 


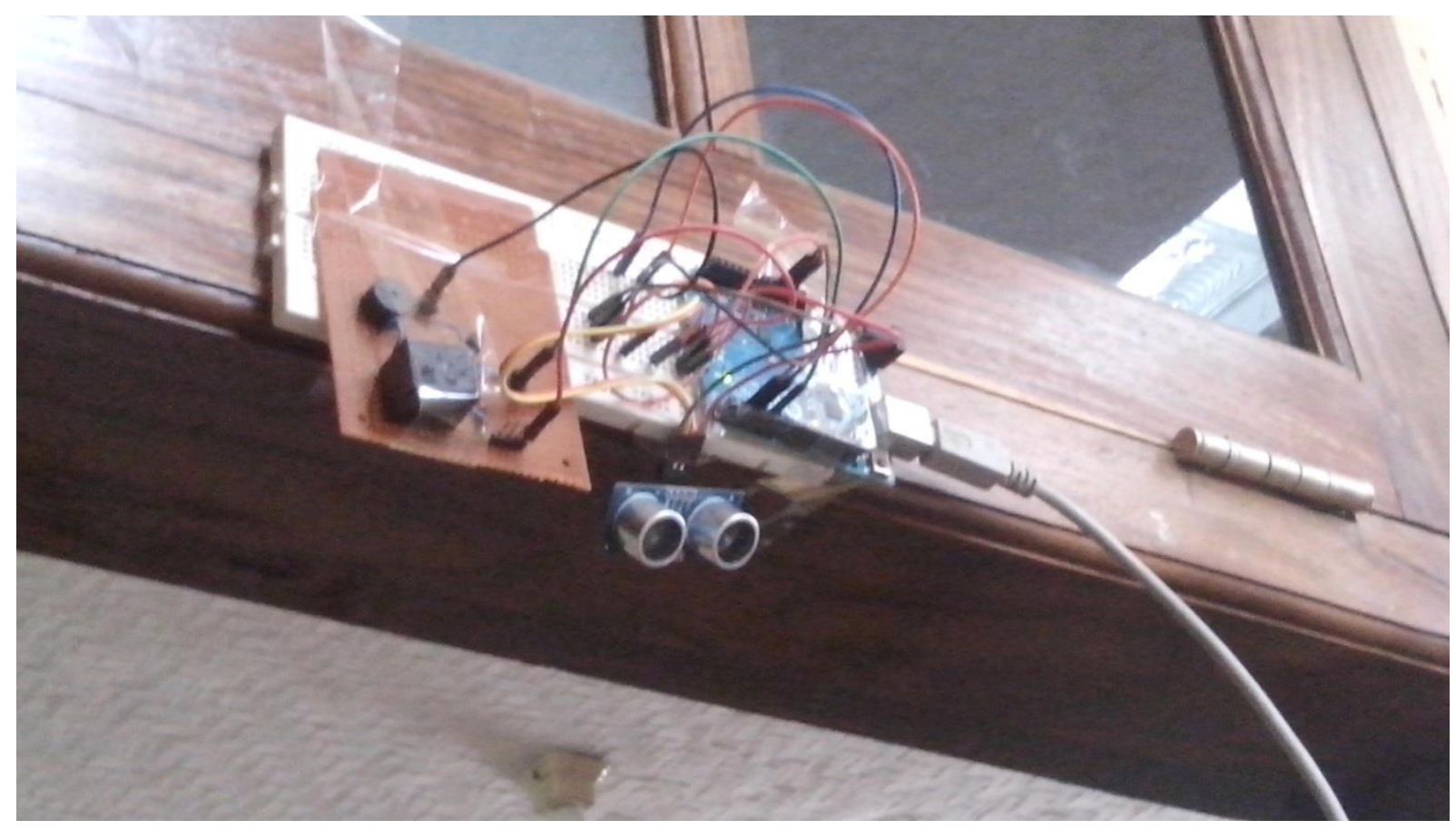

\section{Gambar 7. Peletakan sensor di depan pintu dengan kisaran sudut sensor antara $15^{\circ}-2^{\circ}$}

Untuk mengetahui range kerja sistem, pengunjung yang terdeteksi dan mengaktifkan sensor akan diukur jaraknya terhadap pintu dan sensor. Pengukuran jarak tersebut akan dilakukan menggunakan meteran.

Prosedur pengujian sistem bel otomatis terdiri atas langkah-langkah berikut:

1. Memasang sensor pada kusen pintu dengan sudut antara 15 hingga 20 derajat terhadap pintu. Setelah pemasangan selesai, mengukur dan mencatat tinggi sensor dari tanah dan kemiringan persis dari sensor.

2. Pada permulaan, subyek pengujian ditempatkan di luar jangkauan sensor. Subyek kemudian diminta berjalan mendekati pintu secara perlahan hingga akhirnya bel berbunyi.

3. Pada kondisi ini, rangkaian bel dimatikan dan subyek diminta untuk tetap di tempat.Selanjutnya, dilakukan pengukuran untuk data-data berikut:

a. Tinggi badan subyek

b. Jarak subyek terhadap pintu saat bel berbunyi

Rangkaian kembali diaktifkan setelah pengukuran selesai.

4. Apabila bel tidak berbunyi, cukup catat tinggi badan dari subyek.

5. Untuk mengetahui kinerja sistem, maka rangkaian akan diuji pada sejumlah subyek yang berbeda-beda mulai dari anak-anak hingga orang dewasa. Langkah 2 dan 3 dari percobaan diulangi untuk setiap subyek. Percobaan dilakukan untuk jumlah subyek minimal lima orang.

6. Apabila jumlah subyek percobaan dianggap belum mencukupi, subyek dapat digantikan dengan barang-barang tertentu, misalnya kursi. 


\section{HASIL PENGUJIAN DAN ANALISIS}

\subsection{Hasil Pengujian}

Setelah sistem dipasang pada kusen pintu setinggi $197 \mathrm{~cm}$ dengan modul ultrasonik berada pada ketinggian $192 \mathrm{~cm}$ seperti terlihat pada Gambar 8, maka diperoleh sejumlah data jarak horisontal dan vertikal yang membuat buzzer aktif. Untuk kemiringan sensor 15 derajat, jarak maksimum yang dideteksi oleh sensor adalah $98,5 \mathrm{~cm}$. Jarak horisontal ini diukur dari depan pintu rumah, sedangkan jarak vertikal dihitung dari dasar lantai.Data pengukuran beberapa posisi jarak horisontal dan vertikal tersebut terlihat pada Tabel 2.

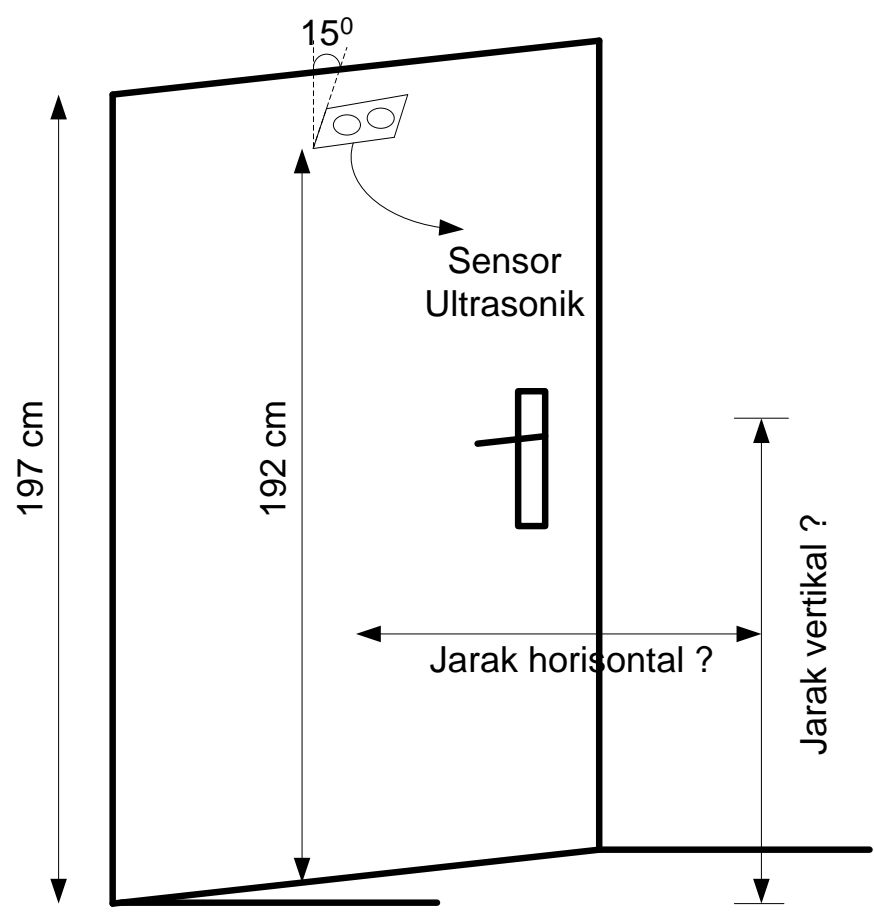

Gambar 8. Diagram blok peletakan sensor di depan pintu dengan sudut sensor $\mathbf{1 5}^{\circ}$

Tabel 2: Hasil pengujian jarak horizontal dan vertikal sistem bel pintu otomatis

\begin{tabular}{|c|c|c|c|c|c|}
\hline No. & $\begin{array}{c}\text { Jarak } \\
\text { vertikal } \\
(\mathbf{c m})\end{array}$ & $\begin{array}{c}\text { Jarak } \\
\text { horisontal } \\
\text { (cm) }\end{array}$ & $\begin{array}{c}\text { Aktivitas } \\
\text { Bel }\end{array}$ & $\begin{array}{c}\text { Error } \\
\text { horisontal } \\
(\mathrm{cm})\end{array}$ & $\begin{array}{c}\text { Error } \\
\text { horisontal } \\
(\%)\end{array}$ \\
\hline 1 & 77 & - & Tidak Aktif & - & \\
\hline 2 & 101 & 50 & Aktif & 10 & 25 \\
\hline 3 & 132 & 40 & Aktif & 0 & 0 \\
\hline 4 & 152 & 55 & Aktif & 15 & 37,5 \\
\hline 5 & 165 & 45 & Aktif & 5 & 12,5 \\
\hline 6 & 166 & 40 & Aktif & 0 & 0 \\
\hline 7 & 175 & 42 & Aktif & 2 & 5 \\
\hline \multicolumn{2}{|c|}{ Rata-Rata } & 45,33 & & 5,33 & 25,33 \\
\hline
\end{tabular}




\subsection{Analisis}

Sistem untuk mengaktifkan bel secara otomatis khususnya untuk anak kecil atau penyandang cacat yang kesulitan menggapai posisi bel di depan pintu dengan menggunakan sensor ultasonik telah berhasil dirancang dan diimplementasikan dalam studi ini. Sistem ini dibangun dengan menggunakan sebuah sensor yang diposisikan dengan kemiringan 15 derajat guna mendeteksi dua jarak yaitu jarak vertikal dan jarak horizontal dari pintu. Hal ini ditujukan untuk menghemat penggunaan sensor, dimana tidak menggunakan dua buah sensor yang diletakkan di depan dan di atas pintu. Selain itu, penggunaan sebuah sensor dapat menyederhanakan implementasi sistem.

Sistem ini sudah dapat bekerja dengan baik untuk mendeteksi dua jarak sekaligus serta mengaktifkan bel yang menandakan adanya obyek (seseorang) di depan pintu. Sistem ini dapat mengantisipasi keberadaan sejenis hewan piaraan seperti kucing, anjing atau ayam di depan pintu untuk mengaktifkan bel. Hal ini dikarenakan ketinggian obyek yang dapat dideteksi adalah $101 \mathrm{~cm}$ dari permukaan.

Jarak minimum yang diperoleh dari sistem ini mungkin masih belum memenuhi spesifikasi yang diinginkan yaitu berbeda sebesar $6 \mathrm{~cm}$. Hal ini dikarenakan adanya keterbatasan dari sensor yaitu penempatan sensor di atas pintu yang masih belum kokoh serta kualitas sensor untuk mendeteksi secara akurat tinggi suatu obyek .Jika didasarkan pada Lampiran 3 buku Pedoman Kegiatan Gizi Dalam Penanggulangan Bencana, Kementerian Kesehatan RI tahun 2012 (www.academia.edu), maka sistem ini mulai dapat digunakan untuk pengunjung anak-anak antara 4-6 tahun (tinggi badan rata-rata yaitu $110 \mathrm{~cm}$ ).

Adapun untuk jarak secara horizontal, sistem ini telah dapat memenuhi pengukuran jarak minimal yang ditentukan dalam spesifikasi sistem yaitu $40 \mathrm{~cm}$ dari depan pintu untuk ketinggian (jarak vertikal) minimum yaitu $132 \mathrm{~cm}$. Berdasarkan pengujian yang dilakukan, diketahui bahwa error terhadap jarak secara horizontal ini terhadap spesifikasi yang ditentukan $(40 \mathrm{~cm})$ adalah 5,33 $\mathrm{cm}$ atau 25,33\%. Kesalahan pengukuran ini memang lebih besar jika dibandingkan kesalahan pengukuran dari penelitian-penelitian sebelumnya yaitu antara $2 \mathrm{~cm}$ hingga $3.44 \mathrm{~cm}$ (Susanto dkk, 2007; Prawiroredjo dan Asteria, 2008; Arief, 2011). Bahkan penelitian dari Karyadi dan Gunawan (Karyadi dan Gunawan, 2007) menunjukkan kesalahan rata-rata pengukuran yang lebih kecil yaitu $0,94 \mathrm{~cm}$. Perbedaan ini disebabkan karena jenis sensor ultrasonik yang digunakan oleh peneliti sebelumnya berbeda dengan yang digunakan, yaitu menggunakan jenis sensor ultrasonik PING dan MaxSonar-EZ1. Selain perbedaan jenis sensor yang digunakan, kesalahan dapat terjadi akibat adanya sinyal yang tidak diharapkan pada frekuensi sama dengan fase berbeda, sehingga terjadi acoustic cancellation yang mengubah sinyal ultrasonik yang diterima

\section{(http://maxbotix.com/documents/LV-MaxSonar-EZ_Datasheet.pdf;} http://www.indiana.edu/ emusic/acoustics/phase.htm).

Dari data yang diperoleh dari pengujian ini dapat diperoleh fakta bahwa kemampuan sensor untuk mendeteksi jarak minimum secara horizontal dipengaruhi pula oleh tinggi obyek suatu benda dari sensor tersebut. Dapatdisimpulkan bahwasensor jenis HC-SR04 relatif baik diimplementasikan pada sistem ini.Akan tetapi, hal ini memang perlu dilakukan pengujian sistem lebih lanjut yaitu dengan menyediakan ketinggian obyek yang lebih variatif. Pada studi ini memang masih belum menampilkan data ketinggian dengan penambahan ketinggian yang lebih teratur. Hal ini dikarenakan sulitnya memperoleh obyek dengan ketinggian yang diinginkan untuk dapat dijadikan sebagai alat uji. 
Untuk pengembangan sistem ini, maka perlu dibuat suatu alat khusus yang dapat diatur ketinggiannya secara teratur untuk dijadikan sebagai alat uji. Hal lain yang perlu dilakukan yaitu pengujian obyek untuk diuji mengaktifkan sistem ini dengan posisi tidak tepat ditengah-tengah posisi pintu. Penulis merasa bahwa pengujian ini perlu dilakukan karena diperkirakan posisi ini pun akan mempengaruhi terhadap kehandalan sistem. Ditambah pula jika sistem ini akan diterapkan bagi penderita tuna netra yang akan sulit menentukan posisi tengah sebuah pintu rumah.

\section{KESIMPULAN}

Berdasarkan implementasi dan pengujian yang telah dilakukan, maka dapat ditarik kesimpulan bahwa sistem bel otomatis telah dapat berfungsi dengan menggunakan sebuah sensor ultrasonic jenis HC-SR04. Melalui penempatan sensor tersebut dengan kemiringan $15^{\circ}$, maka sistem bel otomatis akan aktif saat mendeteksi pengunjung dengan jarak vertikal (tinggi obyek ) minimum $101 \mathrm{~cm}$ dan jarak horizontal rata-rata 45,33 cm. Hasil ini masih memenuhi akurasi $\pm 10 \mathrm{~cm}$ dari spesifikasi yang ditetapkan.

\section{DAFTAR RUJUKAN}

Arief, U. M. (2011). Pengujian sensor ultrasonic PING untuk pengukuran level ketinggian dan volume air. Jurnal Ilmiah Elektrikal Enjiniring UNHAS, Volume 09/No.02/MeiAgustus/2011.

Karyadi, D.S. dan Gunawan, H. (2007). Alat ukur tinggi badan portabel. Widya Teknik Vol. 6 No. 1 , pp. 56-68.

Prawiroredjo, K. dan Asteria, N. (2008). Detektor jarak dengan sensor ultrasonic berbasis mikrokontroler. JETri, Volume 7, Nomor 2, pp. 41-52 (ISSN: 1412-0372).

Susanto, R., Kristanto, Y., Ridwanto, S., Hisnuaji, D. (2007). Perancangan dan implementasi sensor parkir pada mobil menggunakan sensor ultrasonik, CommIT, Vol. 1, No.1, pp. 1829.

Arduino. Arduino Uno. Dipetik Februari 9, 2015, dari www.arduino.cc/en/Main/arduinoBoardUno

Hunston Electronics. Magnetic Buzzer. Dipetik Januari 7, 2015, dari http://www.hsbuzzer.com/technology/Magnetic Buzzer

Kementerian Kesehatan RI (2012). Pedoman Kegiatan Gizi dalam Penanggulangan Bencana. Dipetik Februari 9, 2015, dari https://www.academia.edu/6024671/KEMENTERIAN_KESEHATAN_RI_2012_PEDOMAN_ GIZI_DALAM_PENANGGULANGAN_BENCANA

Indiana University (2003). What is phase? Dipetik Mei 21, 2015, dari http://www.indiana.edu/ emusic/acoustics/phase.htm

ElecFreaks. HC-SR04 Datasheet. Dipetik Mei 30, 2015, dari http://www.micropik.com/PDF/HCSR04.pdf

MaxBotix Inc. LV-MaxSonar-EZ Datasheet. Dipetik Mei 31, 2015, dari http://maxbotix.com/documents/LV-MaxSonar-EZ_Datasheet.pdf 